\title{
Communication \\ Ultra-Highly Sensitive Ammonia Detection Based on Light-Induced Thermoelastic Spectroscopy
}

\author{
Yao Mi and Yufei Ma* (D)
}

Citation: Mi, Y.; Ma, Y. Ultra-Highly Sensitive Ammonia Detection Based on Light-Induced Thermoelastic Spectroscopy. Sensors 2021, 21, 4548. https://doi.org/10.3390/s21134548

Academic Editor: Simona

M. Cristescu

Received: 23 June 2021

Accepted: 1 July 2021

Published: 2 July 2021

Publisher's Note: MDPI stays neutral with regard to jurisdictional claims in published maps and institutional affiliations.

Copyright: (c) 2021 by the authors. Licensee MDPI, Basel, Switzerland. This article is an open access article distributed under the terms and conditions of the Creative Commons Attribution (CC BY) license (https:// creativecommons.org/licenses/by/ $4.0 /)$.
National Key Laboratory of Science and Technology on Tunable Laser, Harbin Institute of Technology, Harbin 150001, China; 1182100107@stu.hit.edu.cn

* Correspondence: mayufei@hit.edu.cn; Tel.: +86-451-8641-3161

\begin{abstract}
This invited paper demonstrated an ultra-highly sensitive ammonia $\left(\mathrm{NH}_{3}\right)$ sensor based on the light-induced thermoelastic spectroscopy (LITES) technique for the first time. A quartz tuning fork (QTF) with a resonance frequency of $32.768 \mathrm{kHz}$ was employed as a detector. A fiber-coupled, continuous wave (CW), distributed feedback (DFB) diode laser emitting at $1530.33 \mathrm{~nm}$ was chosen as the excitation source. Wavelength modulation spectroscopy (WMS) and second-harmonic (2f) detection techniques were applied to reduce the background noise. In a one scan period, a $2 f$ signal of the two absorption lines located at $6534.6 \mathrm{~cm}^{-1}$ and $6533.4 \mathrm{~cm}^{-1}$ were acquired simultaneously. The $2 f$ signal amplitude at the two absorption lines was proved to be proportional to the concentration, respectively, by changing the concentration of $\mathrm{NH}_{3}$ in the analyte. The calculated $\mathrm{R}$-square values of the linear fit are equal to $\sim 0.99$. The wavelength modulation depth was optimized to be $13.38 \mathrm{~mA}$, and a minimum detection limit (MDL) of $\sim 5.85 \mathrm{ppm}$ was achieved for the reported $\mathrm{NH}_{3}$ sensor.
\end{abstract}

Keywords: quartz tuning fork (QTF); light-induced thermoelastic spectroscopy (LITES); ammonia $\left(\mathrm{NH}_{3}\right)$; trace gas detection

\section{Introduction}

Ammonia $\left(\mathrm{NH}_{3}\right)$, a component gas of the atmosphere, has been widely used in various important fields, such as medicine production, chemical industries, and so on [1]. When it comes to a medical diagnostic, $\mathrm{NH}_{3}$ can be used as a biomarker to indicate kidney and liver diseases [2,3]. However, on the other hand, ammonia also has lots of hazards. For example, $\mathrm{NH}_{3}$ poses a serious threat to human health, which can burn skin, eyes, and the respiratory mucosa. If people inhale too much, it can cause lung swelling and even death [4]. $\mathrm{NH}_{3}$ is also the main cause of air pollution. Hence, carrying out ammonia detection is necessary for both industrial production and the environment. Nevertheless, the typical concentration of $\mathrm{NH}_{3}$ is at low levels of parts per million (ppm) or parts per billion (ppb). Therefore, $\mathrm{NH}_{3}$ sensors should be ultra-highly sensitive to satisfy these applications.

Various sensors have been used for $\mathrm{NH}_{3}$ detection. Chemical sensors are widely applied in gas detection, which has the advantages of low cost and small size [5]. However, when chemical sensors are employed to detect $\mathrm{NH}_{3}$, it may be influenced by other gasses, such as oxygen [6]. Laser absorption spectroscopy (LAS) is an effective method with the advantages of being non-invasive, highly sensitive, having a fast response, and selective detection, and has been widely used for trace gas sensing. Tunable diode laser absorption spectroscopy (TDLAS) is a serviceable LAS-based technique to detect the concentration of $\mathrm{NH}_{3}$ [7]. To obtain an excellent detection performance, a multi-pass gas cell (MPGC) is employed in the TDLAS technique [8]. When the laser beam travels through the MPGC, the effective optical path length can be extended to a significant scale, which can bring the detection limit down to ppm levels $[9,10]$. However, adopting an MPGC means the total equipment is costly and bulky by virtue of the large size of an MPGC and the large quantity of optical elements used to align the laser beam. 
Quartz-enhanced photoacoustic spectroscopy (QEPAS), which was reported in 2002 for the first time [11], is another effective method for trace gas detection. A quartz tuning fork (QTF) is employed in QEPAS to transform acoustic wave signals to piezoelectric signals, whose amplitude reflects the gas concentration. The QTF has the advantages of being commercially available, low cost, having a tiny volume, a dipole structure, a high $\mathrm{Q}$-factor, a wide dynamic range, and a narrow resonance frequency band. Due to these advantages, QEPAS could be excellent for sensitive detection and obtain great immunity to environmental noise [12-18]. A sensitive $\mathrm{NH}_{3}$-QEPAS sensor achieving the minimum detection limit (MDL) of $418.4 \mathrm{ppb}$ was reported in 2017 [19]. In QEPAS, the QTF needs to be placed in the gas cell and immersed in the target gas. When using QEPAS to detect the concentration of corrosive gases such as $\mathrm{NH}_{3}$, the QTF can be corroded, which may finally bring sensor failure.

Light-induced thermoelastic spectroscopy (LITES), an effective technique first reported in 2018 [20], has been widely employed for trace gas detection. This technique is also named quartz-enhanced photothermal spectroscopy (QEPTS). In LITES, the laser beam is focused on the QTF after traveling through the sample gas cell and being absorbed. Hence, when the laser arrives at the QTF, its power is converted into thermal energy in the quartz crystal [21-23]. Due to thermoelastic deformation, the periodic change of laser energy contributes to the periodic mechanical motion of QTF prongs, which would be enhanced by the resonance property of QTF [24,25]. Because of the piezoelectric effect, the QTF transforms mechanical vibrations into electrical signals. By demodulating the electrical signal, the concentration of sample gas can be obtained [26,27]. Compared to QEPAS, LITES has the same advantages as QEPAS while avoiding the QTF damage caused by target gas corrosiveness [28]. Therefore, LITES has been widely used in corrosive gas detection [29]. However, till now, $\mathrm{NH}_{3}$ detection using the LITES technique has not been reported.

In this invited manuscript, an ultra-highly sensitive $\mathrm{NH}_{3}$ sensor based on the LITES technique is demonstrated for the first time. By means of wavelength modulation spectroscopy (WMS) and second-harmonic detection (2f) techniques, the background noise of the sensor was able to dropdown. One current scan period covered two different absorption lines of $\mathrm{NH}_{3}$. By changing the concentration of $\mathrm{NH}_{3}$ in the analyte, a linear relationship between $2 f$ signal amplitude and concentration was demonstrated. After optimizing the response time and modulation depth, an MDL of $\sim 5.85 \mathrm{ppm}$ was achieved for this reported $\mathrm{NH}_{3}$-LITES sensor.

\section{Experimental Setup}

\subsection{Absorption Line Selection}

Diode lasers have many merits, such as a wide tunable range from near-ultraviolet to near-infrared, small size, narrow linewidth, and high optical efficiency, making them have important applications in single-chip laboratory, medical diagnosis, dermatology, and gas sensing. In this experiment, a fiber-coupled, near-infrared, continuous wave (CW), distributed feedback (DFB) diode laser emitting at $1530.33 \mathrm{~nm}$ was chosen to be the excitation source. By changing the injection current at different temperatures, the emission characteristic of this diode laser was measured. The results are shown in Figure 1. Considering that the LITES signal has wide dynamic responses to laser power [20], the output power of the CW-DFB diode laser can meet the demand.

Considering that different gases may influence the detection, the absorption lines of $\mathrm{NH}_{3}, \mathrm{H}_{2} \mathrm{O}$, and $\mathrm{CO}_{2}$ located between $1425 \mathrm{~nm}$ and $1600 \mathrm{~nm}$ were calculated respectively based on the HITRAN 2016 database [30]. As is shown in Figure 2a, the existence of $\mathrm{CO}_{2}$ or $\mathrm{H}_{2} \mathrm{O}$ could not influence the $\mathrm{NH}_{3}$ detection. Considering that the CW-DFB diode laser chosen in this experiment is able to cover the wavelength from $1530.69 \mathrm{~nm}\left(6533 \mathrm{~cm}^{-1}\right)$ to $1529.99 \mathrm{~nm}\left(6536 \mathrm{~cm}^{-1}\right)$, two absorption lines of $\mathrm{NH}_{3}$, which are respectively located at $1530.33 \mathrm{~nm}\left(6534.6 \mathrm{~cm}^{-1}\right)$ and $1530.60 \mathrm{~nm}\left(6533.4 \mathrm{~cm}^{-1}\right)$, were chosen in this investigation. The selected absorption lines are depicted in Figure $2 \mathrm{~b}$. 


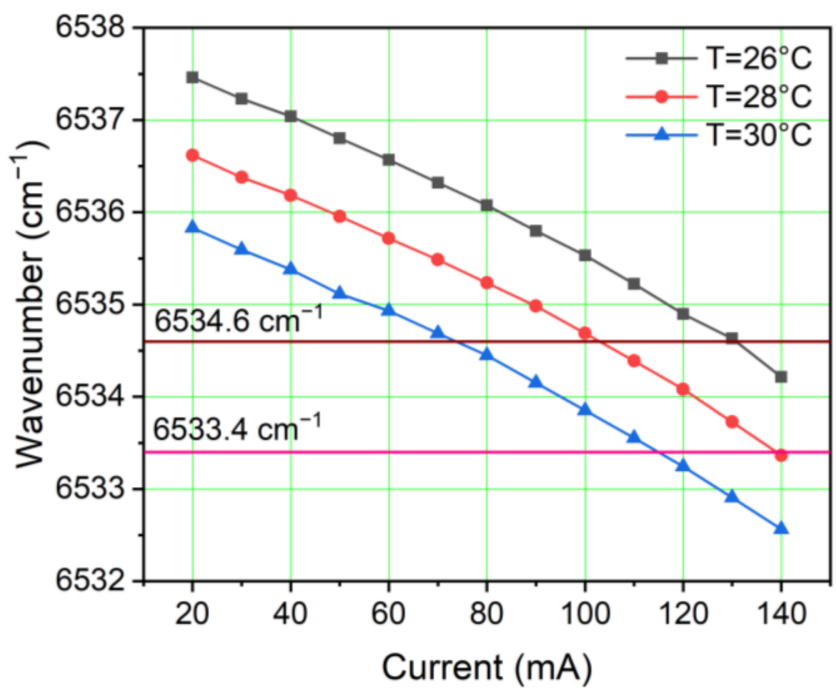

Figure 1. Emission characteristic of the $1530.33 \mathrm{~nm} \mathrm{CW}$-DFB diode laser.

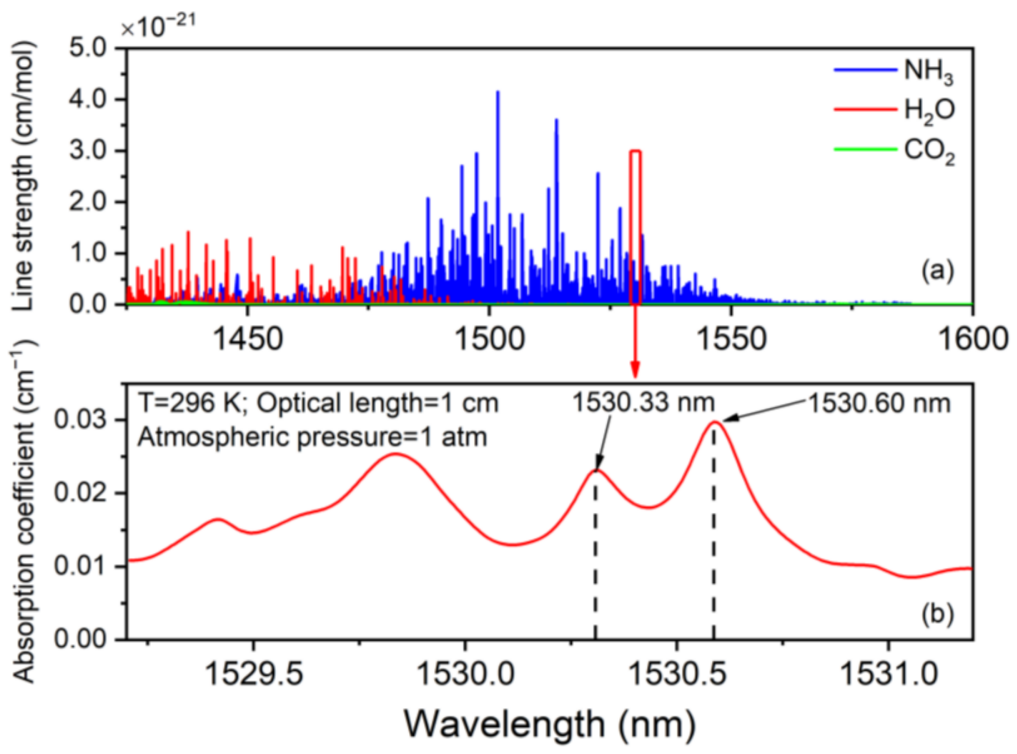

Figure 2. Simulation absorption spectra based on HITRAN database: (a) absorption line strength of different gases; (b) absorption coefficient of $\mathrm{NH}_{3}$ at $296 \mathrm{~K}$, standard atmospheric pressure, and an optical path length of $1 \mathrm{~cm}$ for 10,000 $\mathrm{ppm} \mathrm{NH}_{3}: \mathrm{N}_{2}$.

\subsection{The Configuration of Experimental Setup}

A schematic diagram of the LITES sensor system is exhibited in Figure 3. A fiber collimator (FC) was employed in order to collimate the laser beam generated by the fibercoupled, CW-DFB diode laser. Afterward, the laser beam traveled through the absorption cell with a length of $20 \mathrm{~cm}$ and filled with target gas. To avoid optical interference, two wedged $\mathrm{CaF}_{2}$ windows were installed on both sides of the absorption cell. Subsequent to propagating through the cell, the laser beam is focused by a lens with a focal length of $40 \mathrm{~mm}$ on a QTF with a low intrinsic resonance frequency $f_{0}$ of $32.768 \mathrm{kHz}$ in a vacuum. For the purpose of acquiring the maximum signal, the position where the laser beam focuses on the QTF's surface is supposed to be optimized. As was reported in [31], the optimum laser focusing position is the bare surface area on the base of QTF's prongs. WMS and $2 f$ detection techniques were adopted in this LITES sensor system. An adder was employed for the CW-DFB laser, which added a low-frequency ramp wave generated by a signal generator and a high-frequency sinusoidal wave $\left(f=f_{0} / 2=15.36 \mathrm{kHz}\right)$ generated 
by a lock-in amplifier together. The ramp wave contributed to continuously changing the emission wavelength of the CW-DFB diode laser across the absorption lines of $\mathrm{NH}_{3}$. The demodulated $2 f$ component of the LITES signal could be acquired by a lock-in amplifier. In this reported $\mathrm{NH}_{3}$-LITES sensor system, the integration time of the lock-in amplifier was $200 \mathrm{~ms}$. The experiment was accomplished at room temperature and atmospheric pressure. The LITES technique has wide dynamic responses to gas concentration [20]; therefore, a certified gas mixture of $10,000 \mathrm{ppm} \mathrm{NH} \mathrm{N}_{3}: \mathrm{N}_{2}$ was utilized as the analyte. The experimental results were verified by repeated measurements.

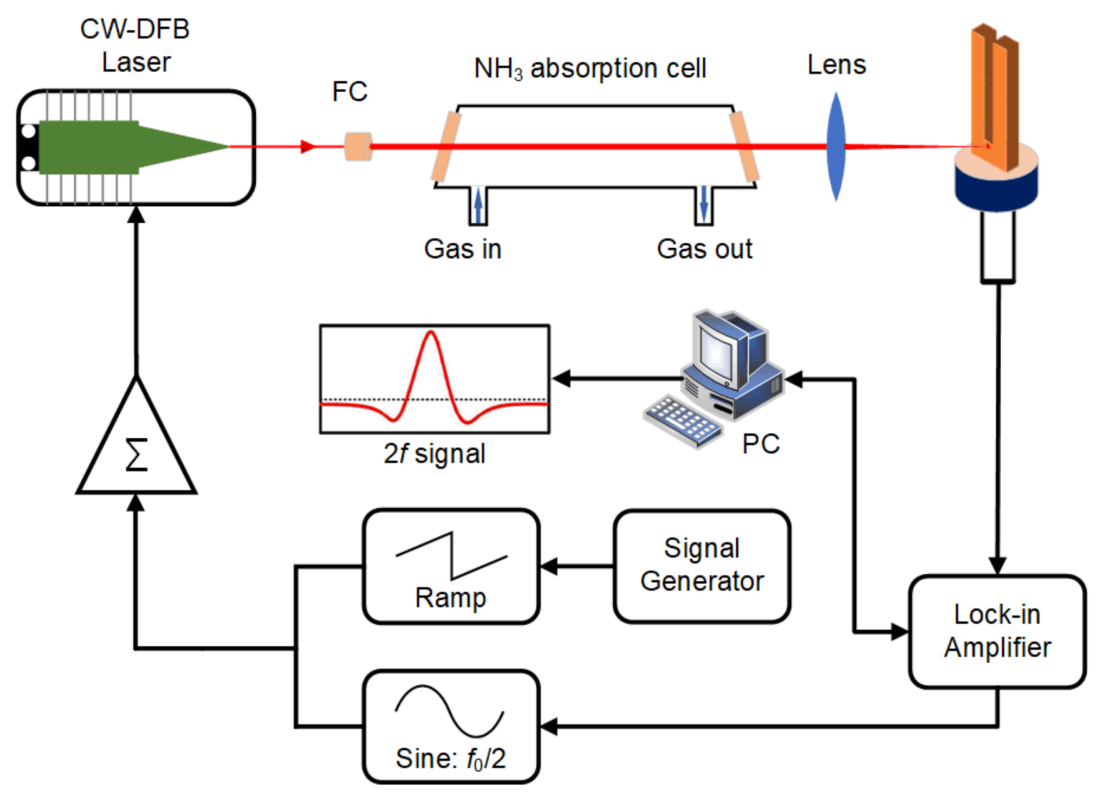

Figure 3. Schematic diagram of the LITES sensor system.

\section{Experimental Results and Discussion}

Firstly, the QTF's properties were investigated. There are two methods to investigate the QTF's properties. The first one applies a laser beam as the excitation source [27]; the other one applies electric excitation [32]. The first method was adopted in this experiment. As is shown in Figure 4, the intrinsic resonance frequency $f_{0}$ and bandwidth $\Delta f$ were measured as $32.763 \mathrm{kHz}$ and $2.25 \mathrm{~Hz}$, respectively. The quality factor $Q=f_{0} / \Delta f$ was calculated as 14,541 , indicating its good performance.

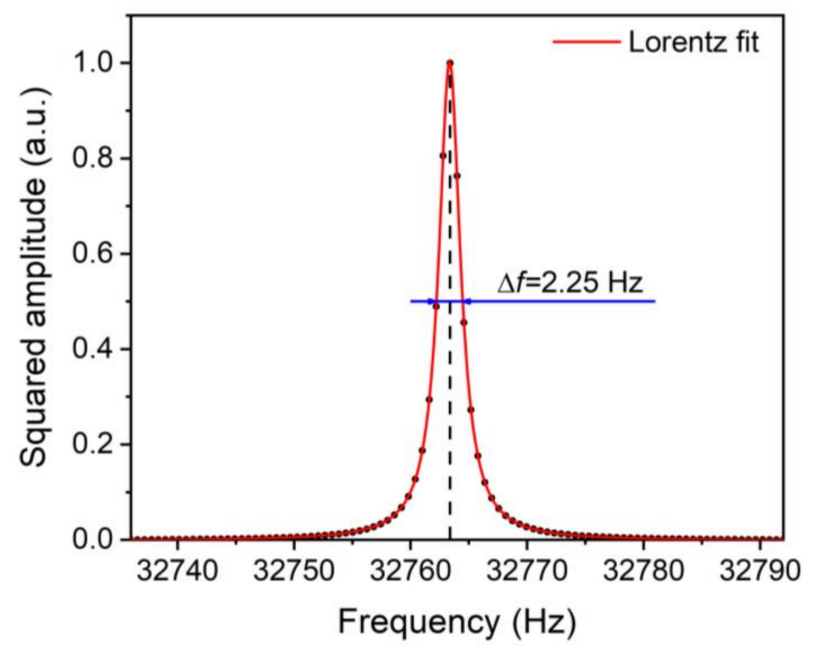

Figure 4. Normalized and squared amplitude as a function of frequency. 
Considering that $\mathrm{NH}_{3}$ is able to be adsorbed onto the inner surface of the absorption cell, the detected $2 f$ signal is unstable before $\mathrm{NH}_{3}$ is in a saturation adsorption state. Hence, it is crucial to investigate the relationship between the $2 f$ signal value and ventilation time. The measured results are exhibited in Figure 5. The results indicate that the normalized signal value is essentially stable after $400 \mathrm{~s}$. Hence, to acquire stable experimental data, the experiment is expected to be carried out at least $400 \mathrm{~s}$ after the $\mathrm{NH}_{3}$ injection.

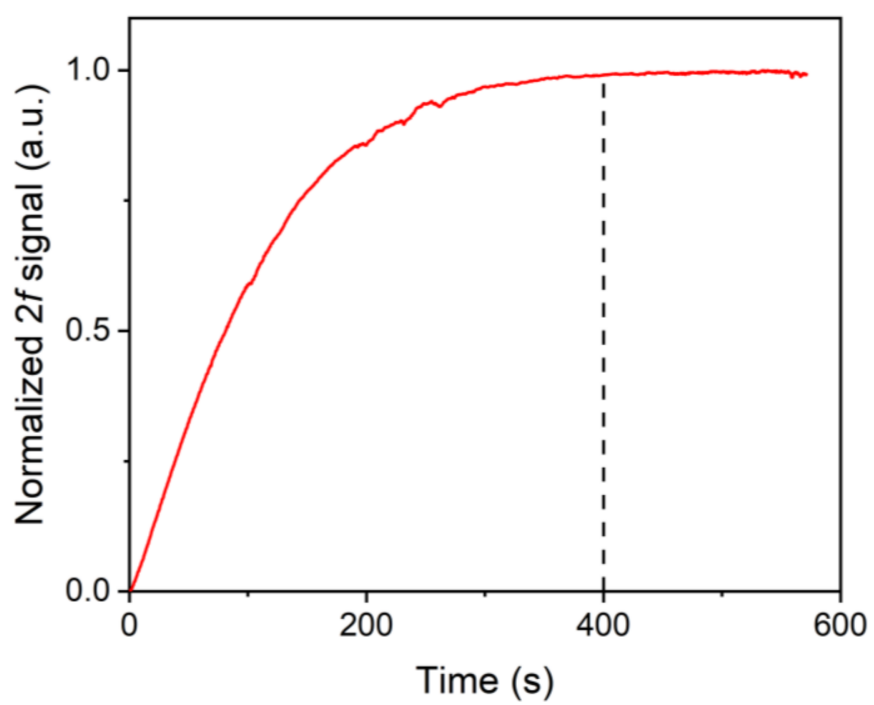

Figure 5. The correlation between normalized $2 f$ signal value and ventilation time.

Figure 6 reflects the correlation between the $\mathrm{NH}_{3}$-LITES signal value and wavelength modulation depth. In this paper, wavelength modulation depth is described by injection current. It could be seen that the $\mathrm{NH}_{3}$-LITES signal amplitude rose to a maximum first and then fell down with the increase in injection current. When the wavelength modulation depth was $13.38 \mathrm{~mA}$, the $2 f$ signal achieved the maximum value. Therefore, the optimum modulation depth of $13.38 \mathrm{~mA}$ was used in the following investigations.

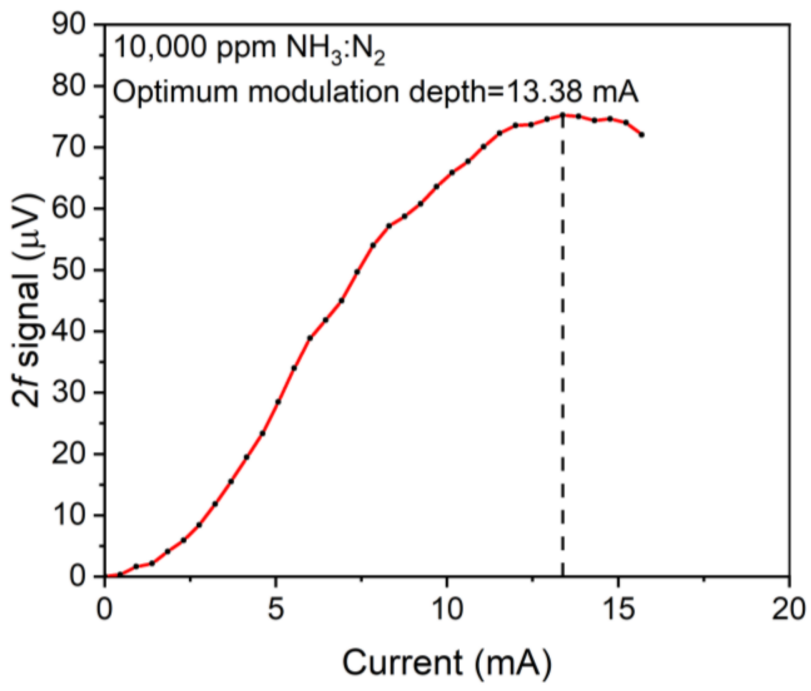

Figure 6. The correlation between wavelength modulation depth and $2 f$ signal value.

When the modulation depth was $13.38 \mathrm{~mA}$, the $2 f$ signal was measured and exhibited in Figure 7. The $2 f$ signal had two peaks corresponding to the two absorption lines located at $6534.6 \mathrm{~cm}^{-1}(1530.33 \mathrm{~nm})$ and $6533.4 \mathrm{~cm}^{-1}(1530.60 \mathrm{~nm})$, respectively. The peak value 
at $6533.4 \mathrm{~cm}^{-1}$ was $75.23 \mu \mathrm{V}$, while the other peak value was $24.89 \mu \mathrm{V}$. Obviously, the peak value at $6533.4 \mathrm{~cm}^{-1}$ was much bigger than what was located at $6534.6 \mathrm{~cm}^{-1}$, which agreed with the absorption line strength data from the HITRAN database well. Hence, the absorption line located at $6533.4 \mathrm{~cm}^{-1}$ was selected to carry out further investigation. The background noise level was determined by continually monitoring the amplitude for $120 \mathrm{~s}$ when the absorption cell was filled with nitrogen $\left(\mathrm{N}_{2}\right)$. The results are shown in Figure $7 \mathrm{~b}$. The calculated $1 \sigma$ noise value was $0.044 \mu \mathrm{V}$. In terms of the data depicted in Figure $7, \mathrm{a}$ signal-to-noise ratio (SNR) value of $\sim 1709$ was calculated. In view of the definition that minimum detection limit $(\mathrm{MDL})=$ analyte concentration/SNR, an MDL of $\sim 5.85 \mathrm{ppm}$ was acquired for this $\mathrm{NH}_{3}$-LITES sensor.

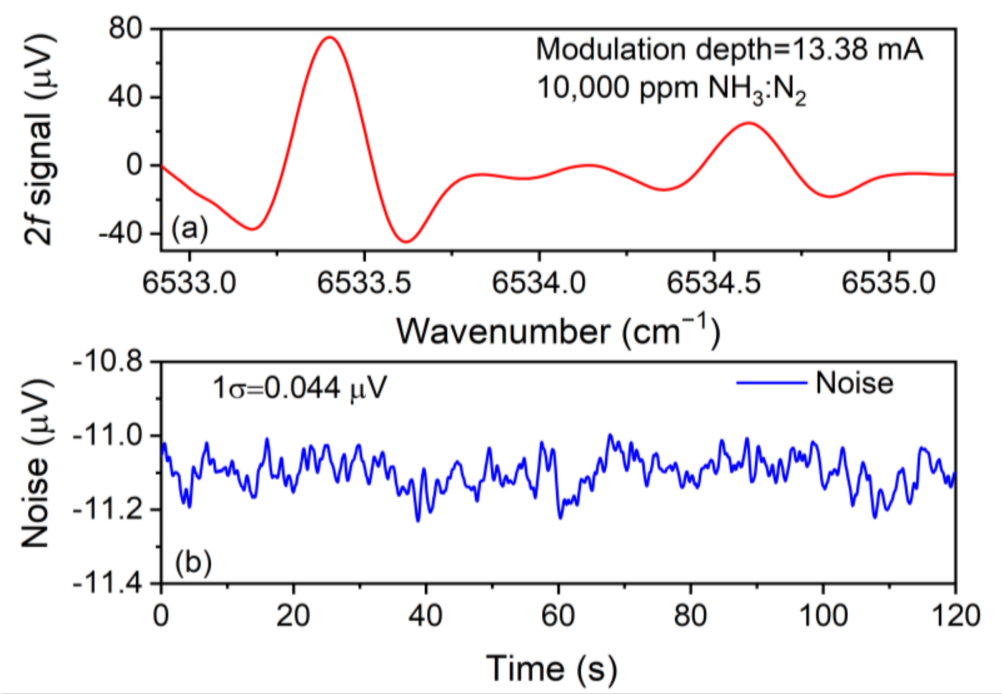

Figure 7. (a) $2 f$ signal of 10,000 ppm $\mathrm{NH}_{3}: \mathrm{N}_{2}$; (b) noise level of $\mathrm{NH}_{3}$-LITES sensor.

To verify the linear response of the LITES signal on the $\mathrm{NH}_{3}$ concentration, the $2 f$ signals for different $\mathrm{NH}_{3}$ concentrations are shown in Figure 8. To obtain a mixture gas of different concentrations, two mass flow controllers were employed to control the gas flow rate of 10,000 ppm $\mathrm{NH}_{3}: \mathrm{N}_{2}$ and pure $\mathrm{N}_{2}$, respectively. Linear fits of LITES signal amplitude and $\mathrm{NH}_{3}$ concentration are shown in Figure 9, respectively, for the two absorption lines. The calculated R-square values are equal to $\sim 0.99$, indicating that the LITES signal performs a splendid linear response of $\mathrm{NH}_{3}$ concentration levels for the two selected lines.

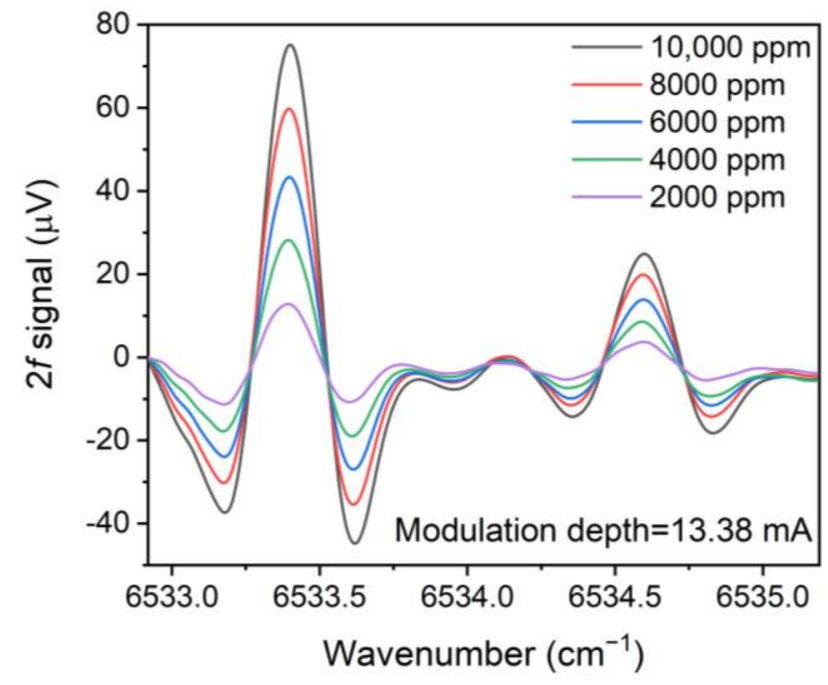

Figure 8. $2 f$ signal of mixture gas with different $\mathrm{NH}_{3}$ concentrations. 


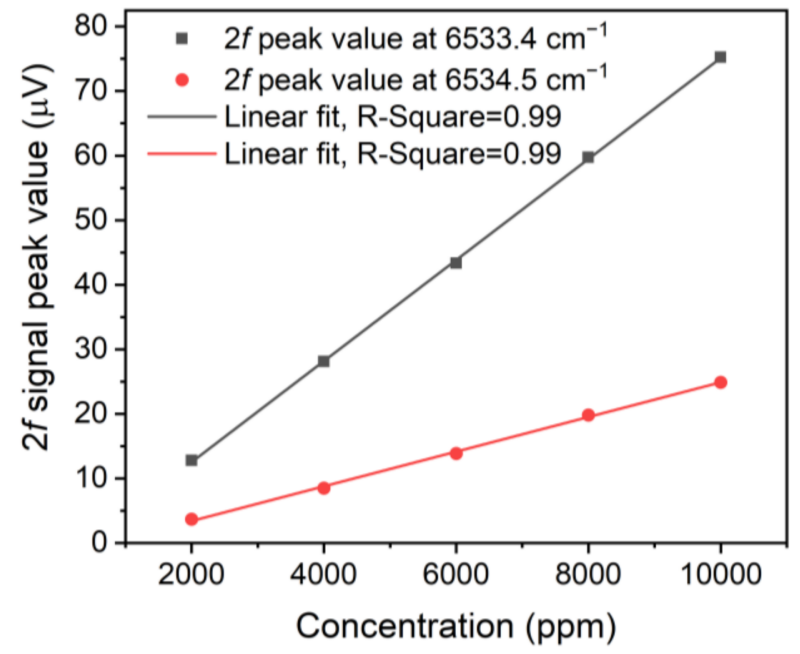

Figure 9. Linear fits of $2 f$ signal peak values and $\mathrm{NH}_{3}$ concentration.

\section{Conclusions}

This paper demonstrated an ultra-highly sensitive $\mathrm{NH}_{3}$ sensor based on the LITES technique for the first time. A fiber-coupled, near-infrared, CW-DFB diode laser emitting at $1530.33 \mathrm{~nm}$ was chosen to be the excitation source. A QTF with an intrinsic resonance frequency $f_{0}$ of $32.768 \mathrm{kHz}$ was used as a detector to transduce mechanical vibrations into electrical signals. By means of WMS and $2 f$ detection techniques, the background noise of the sensor was reduced to a low level. Two different absorption lines of $\mathrm{NH}_{3}$ located at $6534.6 \mathrm{~cm}^{-1}$ and $6533.4 \mathrm{~cm}^{-1}$ were chosen and investigated. The response of the LITES signal on the $\mathrm{NH}_{3}$ concentrations was investigated, which indicated an excellent linear response. The wavelength modulation depth was optimized to be $13.38 \mathrm{~mA}$, and finally, an MDL of $\sim 5.85$ ppm was achieved for this $\mathrm{NH}_{3}$-LITES sensor. This ppm-level $\mathrm{NH}_{3}$-LITES sensor has the potential to be applied in environmental monitoring, medical diagnostic, and other fields.

Author Contributions: Investigation; writing—original draft preparation, Y.M. (Yao Mi); writingreview and editing; supervision, Y.M. (Yufei Ma). All authors have read and agreed to the published version of the manuscript.

Funding: This research was funded by National Natural Science Foundation of China (Grant Nos. 62022032, 61875047 and 61505041), Natural Science Foundation of Heilongjiang Province of China (Grant No. YQ2019F006), Fundamental Research Funds for the Central Universities, Financial Grant from the Heilongjiang Province Postdoctoral Foundation (Grant No. LBH-Q18052).

Institutional Review Board Statement: Not applicable.

Informed Consent Statement: Not applicable.

Data Availability Statement: The data presented in this study are available on request from the corresponding author.

Conflicts of Interest: The authors declare no conflict of interest.

\section{References}

1. Jiménez, I.; Vilà, A.M.; Calveras, A.C.; Morante, J.R. Gas sensing properties of catalytically modified wo3 with copper and vanadium for $\mathrm{NH}_{3}$ detection. IEEE Sens. J. 2002, 5, 385-391. [CrossRef]

2. Guntner, A.T.; Abegg, S.; Konigstein, K.; Gerber, P.A.; Schmidt-Trucksäss, A.; Pratsinis, S.E. Breath sensors for health mon-itoring. ACS Sens. 2019, 4, 268-280. [CrossRef] [PubMed]

3. Narasimhan, L.R.; Goodman, W.; Patel, C.K.N. Correlation of breath ammonia with blood urea nitrogen and creatinine during hemodialysis. Proc. Natl. Acad. Sci. USA 2001, 98, 4617-4621. [CrossRef] [PubMed]

4. Fedoruk, M.J.; Bronstein, R.; Kerger, B.D. Ammonia exposure and hazard assessment for selected household cleaning product uses. J. Expo. Anal. Sci. Environ. Epidemiol. 2005, 15, 534-544. [CrossRef] [PubMed] 
5. Majder-Łopatka, M.; Węsierski, T.; Dmochowska, A.; Salamonowicz, Z.; Polańczyk, A. The Influence of Hydrogen on the Indications of the Electrochemical Carbon Monoxide Sensors. Sustainability 2019, 12, 14. [CrossRef]

6. Abkenar, G.N.; Rieu, M.; Breuil, P.; Viricelle, J.-P. Development of a selective ammonia YSZ-based sensor and modeling of its response. Sens. Actuators B Chem. 2021, 338, 129833. [CrossRef]

7. Lu, H.; Zheng, C.; Zhang, L.; Liu, Z.; Song, F.; Li, X.; Zhang, Y.; Wang, Y. A Remote Sensor System Based on TDLAS Technique for Ammonia Leakage Monitoring. Sensors 2021, 21, 2448. [CrossRef]

8. Liu, K.; Wang, L.; Tan, T.; Wang, G.; Zhang, W.; Chen, W.; Gao, X. Highly sensitive detection of methane by near-infrared laser absorption spectroscopy using a compact dense-pattern multipass cell. Sens. Actuators B Chem. 2015, 220, 1000-1005. [CrossRef]

9. Claps, R.; Englich, F.V.; Leleux, D.P.; Richter, D.; Tittel, F.K.; Curl, R.F. Ammonia detection by use of near-infrared diode-laser-based overtone spectroscopy. Appl. Opt. 2001, 40, 4387-4394. [CrossRef]

10. Webber, M.E.; Baer, D.S.; Hanson, R.K. Ammonia monitoring near $1.5 \mu \mathrm{m}$ with diode-laser absorption sensors. Appl. Opt. 2001, 40, 2031-2042. [CrossRef]

11. Kosterev, A.A.; Bakhirkin, Y.A.; Curl, R.F.; Tittel, F.K. Quartz-enhanced photoacoustic spectroscopy. Opt. Lett. 2002, $27,1902-1904$. [CrossRef]

12. Qiao, S.; Ma, Y.; Patimisco, P.; Sampaolo, A.; He, Y.; Lang, Z.; Tittel, F.K.; Spagnolo, V. Multi-pass quartz-enhanced photoacoustic spectroscopy-based trace gas sensing. Opt. Lett. 2021, 46, 977-980. [CrossRef]

13. Ma, Y.; Lewicki, R.; Razeghi, M.; Tittel, F.K. QEPAS based ppb-level detection of CO and N_2O using a high power CW DFB-QCL. Opt. Express 2013, 21, 1008-1019. [CrossRef]

14. Zheng, H.; Liu, Y.; Lin, H.; Liu, B.; Gu, X.; Li, D.; Huang, B.; Wu, Y.; Dong, L.; Zhu, W.; et al. Quartz-enhanced photoacoustic spectroscopy employing pilot line manufactured custom tuning forks. Photoacoustics 2020, 17, 100158. [CrossRef]

15. Feng, W.; Qu, Y.; Gao, Y.; Ma, Y. Advances in fiber-based quartz enhanced photoacoustic spectroscopy for trace gas sensing. Microw. Opt. Technol. Lett. 2021, 63, 2031-2039. [CrossRef]

16. Waclawek, J.P.; Moser, H.; Lendl, B. Compact quantum cascade laser based quartz-enhanced photoacoustic spectroscopy sensor system for detection of carbon disulfide. Opt. Express 2016, 24, 6559-6571. [CrossRef] [PubMed]

17. Li, Y.; Wang, R.; Tittel, F.K.; Ma, Y. Sensitive methane detection based on quartz-enhanced photoacoustic spectroscopy with a high-power diode laser and wavelet filtering. Opt. Lasers Eng. 2020, 132, 106155. [CrossRef]

18. Patimisco, P.; Scamarcio, G.; Tittel, F.K.; Spagnolo, V. Quartz-Enhanced Photoacoustic Spectroscopy: A Review. Sensors 2014, 14, 6165-6206. [CrossRef]

19. Ma, Y.; He, Y.; Tong, Y.; Yu, X.; Tittel, F.K. Ppb-level detection of ammonia based on QEPAS using a power amplified laser and a low resonance frequency quartz tuning fork. Opt. Express 2017, 25, 29356-29364. [CrossRef]

20. Ma, Y.; He, Y.; Tong, Y.; Yu, X.; Tittel, F.K. Quartz-tuning-fork enhanced photothermal spectroscopy for ultra-high sensitive trace gas detection. Opt. Express 2018, 26, 32103-32110. [CrossRef] [PubMed]

21. Russo, S.D.; Zifarelli, A.; Patimisco, P.; Sampaolo, A.; Wei, T.; Wu, H.; Dong, L.; Spagnolo, V. Light-induced thermo-elastic effect in quartz tuning forks exploited as a photodetector in gas absorption spectroscopy. Opt. Express 2020, 28, 19074-19084. [CrossRef] [PubMed]

22. Ma, Y.; He, Y.; Patimisco, P.; Sampaolo, A.; Qiao, S.; Yu, X.; Tittel, F.K.; Spagnolo, V. Ultra-high sensitive trace gas detection based on light-induced thermoelastic spectroscopy and a custom quartz tuning fork. Appl. Phys. Lett. 2020, 116, 011103. [CrossRef]

23. Ma, Y.; Hu, Y.; Qiao, S.; He, Y.; Tittel, F.K. Trace gas sensing based on multi-quartz-enhanced photothermal spectroscopy. Photoacoustics 2020, 20, 100206. [CrossRef] [PubMed]

24. Zhang, Q.; Chang, J.; Cong, Z.; Wang, Z. Application of Quartz Tuning Fork in Photodetector Based on Photothermal Effect. IEEE Photonic. Technol. Lett. 2019, 31, 1592-1595. [CrossRef]

25. Qiao, S.D.; He, Y.; Ma, Y. Trace gas sensing based on single-quartz-enhanced photoacoustic-photothermal dual spectroscopy. Opt. Lett. 2021, 46, 2449-2452. [CrossRef] [PubMed]

26. Lang, Z.T.; Qiao, S.D.; He, Y.; Ma, Y.F. Quartz tuning fork-based demodulation of an acoustic signal induced by pho-to-thermoelastic energy conversion. Photoacoustics 2021, 22, 100272. [CrossRef]

27. Hu, Y.; Qiao, S.; He, Y.; Lang, Z.; Ma, Y. Quartz-enhanced photoacoustic-photothermal spectroscopy for trace gas sensing. Opt. Express 2021, 29, 5121-5127. [CrossRef]

28. Ma, Y. Recent advances in QEPAS and QEPTS based trace gas sensing: a review. Front. Phys. 2020, 8, 268. [CrossRef]

29. Ma, Y.; Lang, Z.; He, Y.; Qiao, S.; Li, Y. Ultra-Highly Sensitive Hydrogen Chloride Detection Based on Quartz-Enhanced Photothermal Spectroscopy. Sensors 2021, 21, 3563. [CrossRef]

30. Gordon, I.E.; Rothman, L.S.; Hill, C.; Kochanov, R.V.; Tan, Y.; Bernath, P.F.; Birk, M.; Boudon, V.; Campargue, A.; Chance, K.V.; et al. The HITRAN2016 molecular spectroscopic database. J. Quant. Spectrosc. Radiat. Transf. 2017, 203, 3-69. [CrossRef]

31. He, Y.; Ma, Y.; Tong, Y.; Yu, X.; Tittel, F.K. Ultra-high sensitive light-induced thermoelastic spectroscopy sensor with a high Q-factor quartz tuning fork and a multipass cell. Opt. Lett. 2019, 44, 1904-1907. [CrossRef]

32. Ma, Y.F.; Yu, G.; Zhang, J.; Yu, X.; Sun, R.; Tittel, F.K. Quartz Enhanced Photoacoustic Spectroscopy Based Trace Gas Sensors Using Different Quartz Tuning Forks. Sensors 2015, 15, 7596-7604. [CrossRef] [PubMed] 